\section{Whale migration record}

SIR-We recently confirmed a new longdistance migration record for mammals (apart from Homo sapiens). We found that a humpback whale (Megaptera novaeangliae) has migrated from the Antarctic peninsula region $\left(64^{\circ} 20^{\prime} \mathrm{S} ; 62^{\circ}\right.$ $\left.27^{\prime} \mathrm{W}\right)$ to Colombia $\left(2^{\circ} 57^{\prime} \mathrm{N} ; 78^{\circ} 12^{\prime} \mathrm{W}\right)$. The shortest swimming distance between these locations is more than 8,334 kilometres. We identified the whale at both locations using photographs of the distinctive ventral pigmentation on the tail flukes ${ }^{1}$. The whale was seen in Antarctica on 19 April and in Colombia on 28 August 1986. This is the first time that a humpback whale has been shown to cross the equator, and the first time an Antarctic humpback whale has been documented in South American waters. This finding has interesting implications for the possibility of migration between hemispheres.

The match of pigmentation was found by comparing a catalogue of 32 humpbacks identified from the Antarctic peninsula $^{2}$ and a collection of 86 identified off the coast of Colombia. The whale swam from Antarctica to Colombia in less than 5 months. Following the typical humpback migration strategy of spending summer in high latitudes and winter in low latitudes ${ }^{3}$, this whale probably belongs to a population that feeds in Antarctica and breeds off the coast of Colombia.

It is also possible that Antarctic peninsula humpback whales migrate up the eastern side of South America to the coast of Brazil, where there is another breeding ground. The swimming distance from the Antarctic peninsula to this area is shorter by more than 1,800 kilometres than to the Colombian site. This raises the interesting possibility that the Antarctic peninsula feeding grounds may be an area from which humpback whales can cross between the South Pacific Ocean and the South Atlantic Ocean. It is of interest to note that only 1,000 kilometres further north of our Colombian study site there is a site used during the breeding season by humpbacks that feed in the Northern Hemisphere (G. H. Steiger, J. Calambokidis and R. Sears, unpublished data).

Despite opposite migration schedules, it might be possible for an occasional individual from the Southern Hemisphere to breed with members of this Northern Hemisphere population. If this also occurred on the east side of South America, it would offer a mechanism for Baker's supposition $^{+}$that the relatively small genetic distance between the North Pacific and North Atlantic populations could be the result of periodic gene flow between oceans. Although previous research clearly demonstrates that most humpbacks probably do not cross the equator or move between oceans, the possibility that individuals occasionally might do so has important implications for gene flow, population differentiation and population management, and deserves further study.

GREGORY S. STONE

NOAA, Undersea Research, R/OR2,

1335 East West High Way,

Silver Spring,

Maryland 20910, USA

Fundacion Yubarta, LILIÁN FLOREZ-GONZALEZ

A.A. 33141 Cali, Valle, Colombia

College of the Atlantic,

STEVEN KATONA

Bar Harbor,

Maine 04609, USA

1. Katona, S.K. \& Whitehead, H. Polar Rec. 20, 439-444 (1981).

2. Stone, G.S. \& Hamner, W. Folar Rec. 24, 15-20 (1988). 3. Mackintosh, N.A. The Stocks of Whales (Fishing News, London, 1965).

4. Baker, C.S. et al. Nature 344, 238-240 (1990).

\section{Rotating gyros and gravity}

SIR-The report by Hayasaka and Takeuchi ${ }^{1}$ that the gravitational acceleration of a rotating mass depends on both the magnitude and vectorial direction of the angular momentum suggests several considerations. It is well known ${ }^{2.3}$ that the motion of an extended body in the Einstein theory of gravitation may depend on spin and angular momentum: the free motion of an extended mass endowed with angular momentum need not be geodesic. There are several theories of gravitation other than Einstein's in which such effects are definitely predicted. Accordingly, excitement at the report of this effect should focus on its size and asymmetry and implications for Einstein's theory of gravitation rather than on the question of whether it exists.

The possibility that angular momentum may influence the gravitational acceleration of a rotating mass was perhaps first noted in 1912 by Nordström ${ }^{+}$in a paper in which he tried to derive a Lorentz invariant theory of gravitation from a scalar potential. Nordström quoted a communication from Einstein, ending: "A simple example shows that in such a theory a rotating object in a gravitational field will have a smaller acceleration than one which is not rotating." Einstein's arguments were never published, and he never subsequently returned in print to the subject.

Explicit calculations of the effect have been published ${ }^{5}$, however. An analogous, extremely elementary calculation for the Einstein equations shows the effect, in contradiction to the results of Papapetrou and Synge, to be (precisely) absent for the case of a small object with the angular momentum vector parallel to the gravitational field.

For the Nordström theory and newtonian theory modified to be compatible with special relativity, the gravitational acceleration of a rotating object is independent of both the mass of the object and the orientation of the angular momentum vector to the field direction. Rather, it depends on (roughly) the average tangential speed in the horizontal plane, when reduction of the acceleration of gravity is of the second order in $v / c$ or about 1 part in $10^{10}$. Qualitatively, it seems to be simply related to the fact that acceleration in special relativity depends, inter alia, on components of the velocity transverse to the acceleration. Similar effects are suggested in many other theories of gravitation.

The meticulous nature of the report of Hayasaka and Takeuchi allows for further experiments by others. It is to be hoped that the arrangement of equipment in some of these tests would measure the dependence of the effect on the magnitude of the polar angle of the angular momentum vector with respect to the vertical.

Department of Physics,

ALEX HARVEY

City University of New York

Flushing, New York 11367-0904, USA

1. Hayasaka, H. \& Takeuchi, S. Phy's. Rev. Lett. 63, 2701 2704 (1989)

Papapetrou, A. Proc. R. Soc. A 64, 57-75; 302-310 (1951); A 209, 248-258 (1951).

Synge, J.L. Relativity: The General Theory (Interscience, New York, 1960)

Nordström, G. Physik Zeitschr. XIII, 1126-1129 (1912). 5. Harvey, A. Ann. Phys 29, 383-390 (1964).

\section{Sunspot cycles and climate}

SIR - Geller in News and Views discussed the implications of a report by James and James $^{2}$ in which an oscillation of about a decade long appeared in power spectra of certain output from a model of the global troposphere. Because the oscillation was generated internally - that is, within the atmospheric model, both authors concluded that "there is no reason to appeal to external forcings to account for ultralow-frequency atmospheric variability". This statement is obviously based on the numerous claims made to attribute approximately decadal cycles in climate timeseries to forcing by the nominal 11-year sunspot cycle, and that so far, no generally accepted and quantitatively based physical mechanism has been provided to explain a connection between solar and atmospheric variability. But if the new general circulation model simulations are correct, they could be interpreted as indicating that the search ${ }^{3}$ for a link between the sunspot cycle and weather 